\title{
Aplikasi Pengolahan Presensi Perkuliahan Dengan Metode Low Fidelity Prototype di STMIK Asia Malang
}

\author{
Adriani Kala'lembang ${ }^{1}$, Mufidatul Islamiyah' ${ }^{2}$ \\ ${ }^{1,2}$ STMIK ASIA Malang \\ ${ }^{1}$ adriani.riny@gmail.com, ${ }^{2}$ mufidatul014@gmail.com
}

\begin{abstract}
ABSTRAK. Sistem absensi dengan teknologi yang ada saat ini dapat diterapkan dalam pengolahan absensi mahasiswa di STMIK Asia Malang karena proses perekapan absensi mahasiswa yang ada di STMIK Asia Malang masih konvensional. Dampak negatif dari rekapitulasi absensi secara konvensional adalah rentan pada mahasiswa yang sering tidak hadir dan titip absen hal ini karena terkadang dosen yang berkaitan tidak dapat mengawasi secara langsung jumlah kehadiran mahasiswa yang banyak. Oleh karena itu sistem ini dirancang agar pengolahan absensi mahasiswa yang ada di STMIK Asia Malang menjadi lebih efektif. Rancang sistem yang digunakan pada jurnal penelitian ini menggunakan metode low fidelity prototype. Hasil pengujian dengan metode black box menunjukkan bahwa antara aksi user dan reaksi sistem telah sesuai dimana sistem ini dapat mengelola data-data pada sistem, serta melakukan pencatatan dan perekapan data absensi. Kata kunci : Absensi; Prototipe.
\end{abstract}

ABSTRACT. Absenteeism system by using present technology can be applied in processing the absenteeism of the student of STMIK Asia Malang, where student absenteeism recap used in STMIK Asia Malang at the moment is carried out conventionally. The negative effects of absenteeism recapitulation conventionally are vulnerable to students who like to absent and entrusted the absence to someone. It is because the lecturer sometimes cannot oversee directly the presence of students in large numbers. Therefore a system is designed in order that student absenteeism processing in STMIK Asia Malang can be more effective. System design used in this journal is using prototype method. The results of this system are able to process data on the system and able to do absenteeism data recording.

Keywords : Absenteeism; prototype.

\section{PENDAHULUAN}

Sistem absensi merupakan hal yang penting dalam sebuah perkuliahan sebagai catatan kehadiran mahasiswa, kehadiran menentukan seseorang mahasiswa berhak mengikuti atau tidak dalam Ujian Tengah Semester (UTS) dan Ujian Akhir Semester (UAS). Presensi kehadiran mahasiawa harus memenuhi syarat $80 \%$ dari 8 pertemuan untuk UTS sedangkan untuk UAS harus $80 \%$ dari 16 pertemuan pada satu semester (Yusuf M dkk, 2016).

Saat ini sistem absensi di Sekolah Tinggi Manajemen dan Ilmu Komputer masih dilakukan secara manual dengan menandatangani lembaran kertas, hal itu tentunya kurang efektif karena membuka kesempatan untuk melakukan kecurangan absensi dengan cara menitipkan tanda tangan teman satu kelas (Aditia Noval dkk, 2013). Selain kecurangan absensi, rekapitulasi oleh Biro Administrasi Akademik (BAA) juga dilakukan dengan cara manual yang membutuhkan waktu yang lama karena harus memasukkan banyak data (Yusuf M dkk, 2016).

Perkembangan teknologi saat ini begitu pesat yang menuntut kita semua untuk berproses lebih cepat seperti halnya absensi dalam kelas. Absensi kelas yang masih konvensional di nilai kurang efektif untuk menunjang pembelajaran di Sekolah Tinggi Manajemen Informatika dan Komputer (STMIK) Asia Malang (Aditia Noval dkk, 2013), oleh sebab itu perkembangan ilmu pengetahuan terutama dalam bidang IT sangat dibutuhkan terutama dalam memperoleh suatu karya atau inovasi maksimal serta memperoleh kemudahan dalam segala aktivitas untuk mencapai tujuan. Salah satu perkembangan teknologi informasi yang penting adalah semakin dibutuhkannya alat pengolahan data yang berfungsi untuk menghasilkan informasi yang di butuhkan dalam alat pengolahan data yang berupa komputer (Hartono Puji dkk, 2015).

Penulisan jurnal ini bertujuan untuk mengolah absensi mahasiswa dengan metode prototyping, dimana prototype merupakan model dari suatu system dalam membangun proses perancangan atau bentuk awal dari suatu objek yang akan dirancang. Ada beberapa cara yang dapat di gunakan dalam prsoses prototyping antara lain : low fidelity prototype methods, high fidelity prototype methods dan fidelity refers to the level of detail (Streng Sara, 2008).

Low findelity prototype methods merupakan design yang paling mudah, murah dan cepat dalam mendesain hanya beberapa jam (Streng Sara, 2008), oleh karena itu pada penelitian ini menggunakan metode ini. Disamping itu kelebihan Low findelity prototype methods memungkinkan orang non-teknis untuk berinteraksi dengan mudah pada tim design dan tidak terhalang dengan teknologi, serta memungkinkan tim design untuk mengevaluasi lebih banyak pilihan design dengan cepat (Streng Sara, 2008). Tahapan dengan 
menggunakan metode ini adalah ide - sketsa / Desain Sistem - evaluasi - implementasi - evaluasi (Streng Sara, 2008).

Menu yang tersedia pada design prototype terdiri dari nama mata kuliah serta jumlah mahasiswa yang mengikuti mata kuliah tersebut. Selain mata kuliah dan jumlah mahasiswa sistem ini juga menyediakan banyak mahasiswa yang tidak masuk yang dikelompokna ke dalam tiga kategori yaitu kategori izin, sakit dan alpa, serta hasil akhir dari sistem ini juga dapat menampilkan banyak mahasiswa yang aktif dalam satu semester memenuhi $80 \%$ kehadiran dalam 16 pertemuan atau tidak, bila tidak memenuhi $80 \%$ dari kehadiran otomatis mahasiawa tersebut tidak bisa mengikuti UAS.

\section{METODE}

Metode yang digunakan adalah metode prototype yang bersifat low fidelity prototype. Low fidelity proototype merupakan prototype yang tidak terlalu rinci menggambarkan sistem, mempunyai fungsi atau interaksi yang terbatas, menampilkan desain interface dan hanya menggambarkan konsep pendekatan secara umum. Adapun tahap ptototype dimulai dari identifikasi kebutuhan, desain sistem, pengujian sistem dan implementasi.

\subsection{Identifikasi Kebutuhan}

Peneliti bersama-sama pihak administrasi mengidentifikasi format seluruh perangkat lunak, mengidentifikasi semua kebutuhan dan garis besar sistem yang akan dibuat. Masalah yang ada pada STMIK Asia Malang adalah belum adanya pengolahan presensi perkuliahan secara komputerisasi. Pengolahan yang secara menual mengakibatkan terjadinya kecurangan dalam proses presensi dan proses rekapitulasi yang dilakukan oleh Tata Usaha menjadi terkendala dan memakan waktu yang cukup lama. Untuk mengatasi permasalahan tersebut maka peneliti mencoba memberikan solusi berupa pengolahan presensi secara komputerisasi. Adapun kebutuhan dalam pengolahan presensi perkuliahan terlihat pada gambar 1 dan gambar 2 .

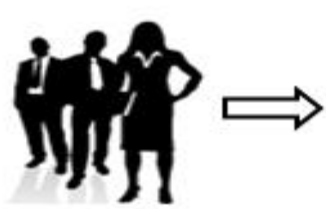

Dosen

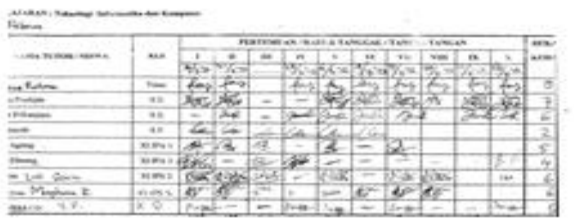

Presensi

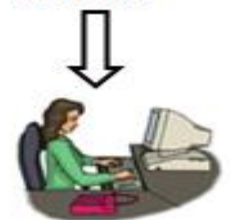

Bagian Kepegawaian

Gambar 1. Sistem yang sedang berjalan

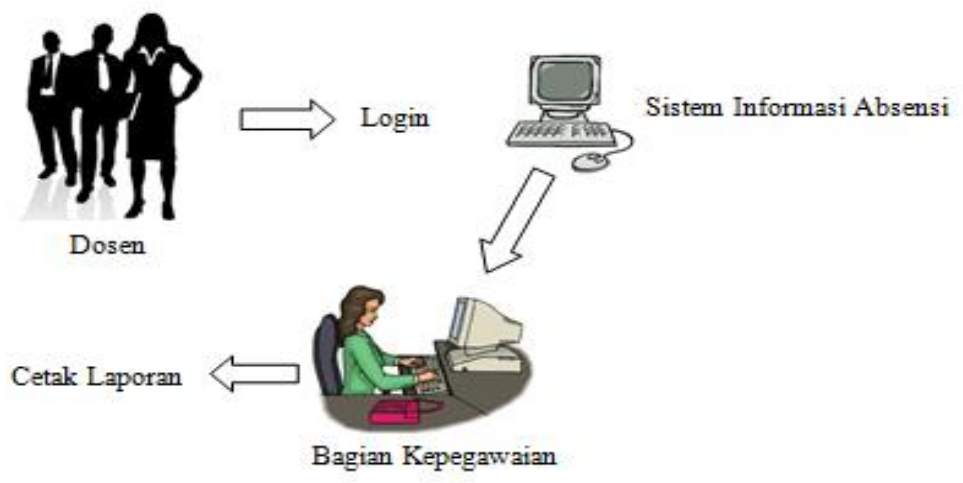

Gambar 2. Sistem yang diusulkan 


\subsection{Desain Sistem}

Pada tahap ini, dilakukan perancangan dan pembuatan prototype sistem. Prototype yang dibuat disesuaikan dengan kebutuhan sistem yang telah didefinisikan sebelumnya dari keluhan pengguna. Adanya perbedaan antara sistem yang lama dengan sistem yang ditawarkan adalah absensi dilakukan secara komputerisasi. Dosen matakuliah yang melakukan absensi secara otomatis akan tersimpan dalam data base dan terekap otomatis dan dapat langsung di cetak oleh tata usaha tanpa harus menginput secara manual. Oleh karena itu diperlukan sebuah sistem yang dapat mempermudah dalam pengolahan absensi agar lebih mudah, Dalam membangun sistem diperlukan sebuah design untuk mempermudah dalam merancang sistem agar sistem yang di buat dapat terstruktural. Sistem pengolahan absensi perkuliahan di rancang menggunakan flowchart diagram (bagan alir), dimana flowchart dibangun untuk menunjukkan aliran di dalam program sistem secara logika. Flowchart digunakan terutama untuk alat bantu komunikasi dan untuk dokumentasi, langkah-langkah dalam flowchart disimbolkan dalam bentuk kotak beserta urutannya dengan menghubungkan masing-masing langkah tersebut menggunakan tanda panah. Flowchart dapat memberikan solusi untuk penyelesaian masalah yang ada di dalam proses atau algoritma tersebut.

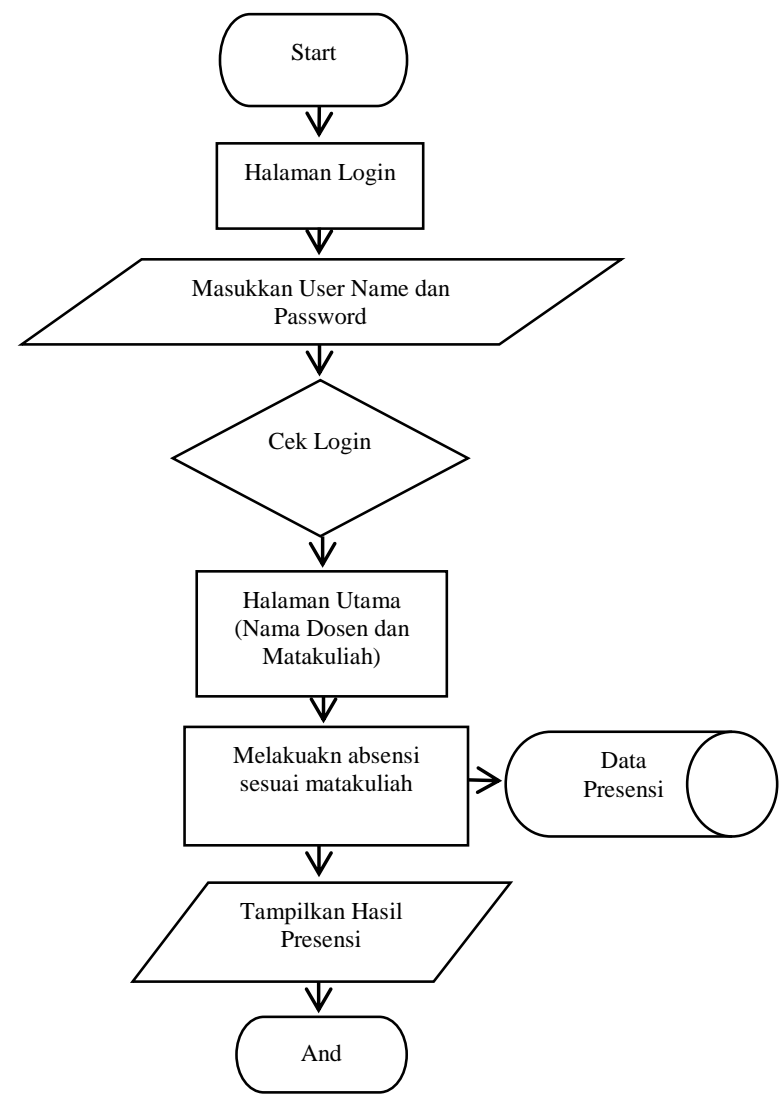

Gambar 3. Flowchart Presensi Mahasiswa

Flowchart di atas merupakan alur dari sistem yang diusulkan untuk melakukan presensi mahasiswa. Adapun pemaparan dari diagram flowchart di atas adalah sebagai berikut.

1. Pertama user akan masuk pada halaman login.

2. Mengisi user name dan password yang telah diberikan pada user sebelumnya dalam hal ini adalah dosen.

3. Kemudian sistem akan mengecek apakah dosen telah benar memasukkan user name dan password. Jika berhasil maka lanjut ke langkah berikutnya, jika tidak maka user (dosen) akan memulai dari awal lagi.

4. Setelah berhasil melakukan login, maka sistem akan membawa user (dosen) pada halaman utama. Dimana pada halaman utama akan dilakukan pembacaan data absensi mahasiswa.

5. Kemudian user (dosen) memilih absensi sesuai dengan matakuliah yang diampuh pada hari itu dan melakukan presensi terhadap mahasiswa. 
6. Setelah melakukan absensi maka data tersebut akan tersimpan pada database dan akan diolah oleh sistem.

7. Data absensi mahasiswa yang telah tersimpan dapat ditampilkan untuk mengetahui siapa saja yang hadir, sakit, izin dan alpa

8. Setelah melakukan absensi dan melihat hasil absensi, user (dosen) dapat menutup halaman utama.

Hasil dari absensi mahasiswa dapat di cetak oleh bagian kepegawaian dalam hal ini BAA tanpa harus menginputkan satu persatu absensi dari mahasiswa. Adapun alur dari proses cetak laporan pada BAA dapat di gambarkan pada flowchart di bawah.

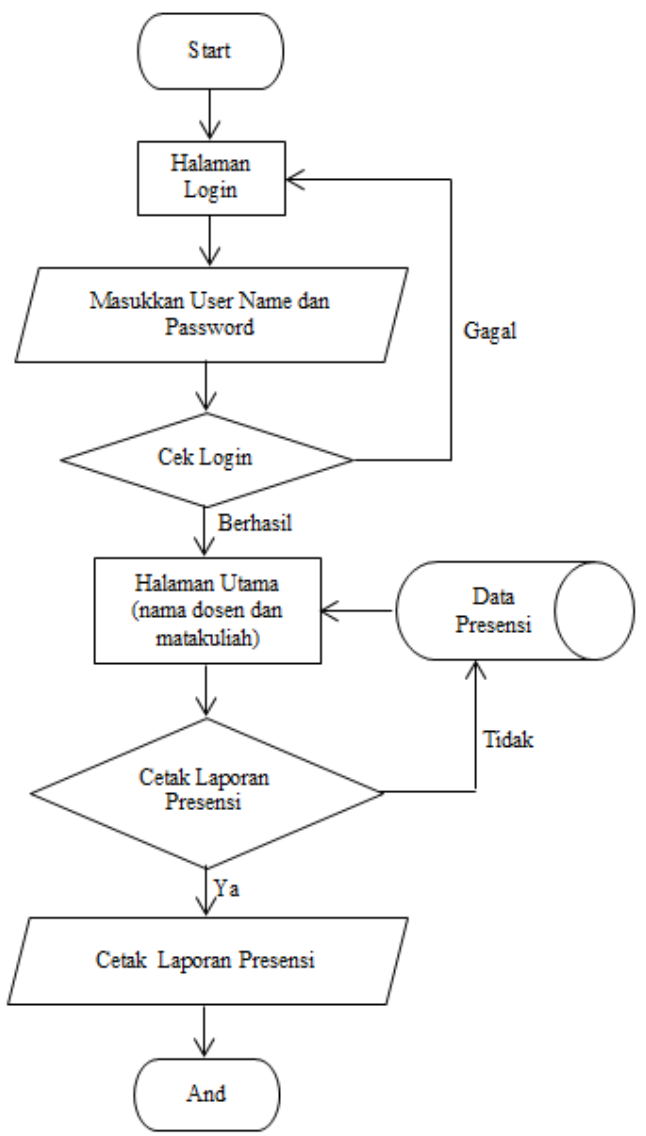

Gambar 4. Flowchart Cetak Laporan oleh BAA

Adapun pemaparan dari alur flowchart di atas adalah sebagai berikut.

1. Pertama user akan masuk pada halaman login.

2. Mengisi user name dan password yang telah diberikan pada user sebelumnya dalam hal ini adalah BAA.

3. Kemudian sistem akan mengecek apakah user (BAA) telah benar memasukkan user name dan password. Jika berhasil maka lanjut ke langkah berikutnya, jika tidak maka user (BAA) akan memulai dari awal lagi.

4. Setelah berhasil melakukan login, maka sistem akan membawa user (BAA) pada halaman utama. Dimana pada halaman utama akan dilakukan pembacaan data dosen dan matakuliah yang di ampu oleh dosen bersangkutan.

5. Kemudian user (BAA) memilih nama dosen dan matakuliah yang bersangkutan untuk mencetak laporan yang telah tersedia pada database.

6. Sistem akan memberi pilihan apakah BAA akan melakukan cetak laporan atau tidak. Jika ia maka akan lanjut ke cetak laporan, jika tidak maka sistem akan membawa kembali BAA pada halaman awal yang telah menampilkan data dosen dan matakuliah yang diampu. 
7. Setelah melakukan proses cetak laporan, BAA dapat mengakhiri proses cetak laporan presensi mahasiswa.

\subsection{Pengujian Sistem}

Pada tahap ini, model sistem di uji secara berulang yang bertujuan untuk menemukan kesalahan yang terjadi kemudian melakukan perbaikan kembali terhadap sistem hingga sesuai dengan kebutuhan user.

\subsection{Implementasi}

Setelah prototype di terima oleh pengguna, maka pada tahap ini menerapkan sistem yang telah siap dan selanjutnya terjadi proses pembelajaran terhadap sistem baru.

\section{HASIL DAN PEMBAHASAN}

Agar mempermudah pengolahan absensi perkuliahan di STMIK Asia Malang, maka dibuatlah aplikasi pengolahan absensi tersebut dengan metode prototype.

\subsection{Form Login}

Pada form login ini merupakan halaman awal dimana pengguna memasukkan username dan password yang telah diregistrasi sebelumnya.

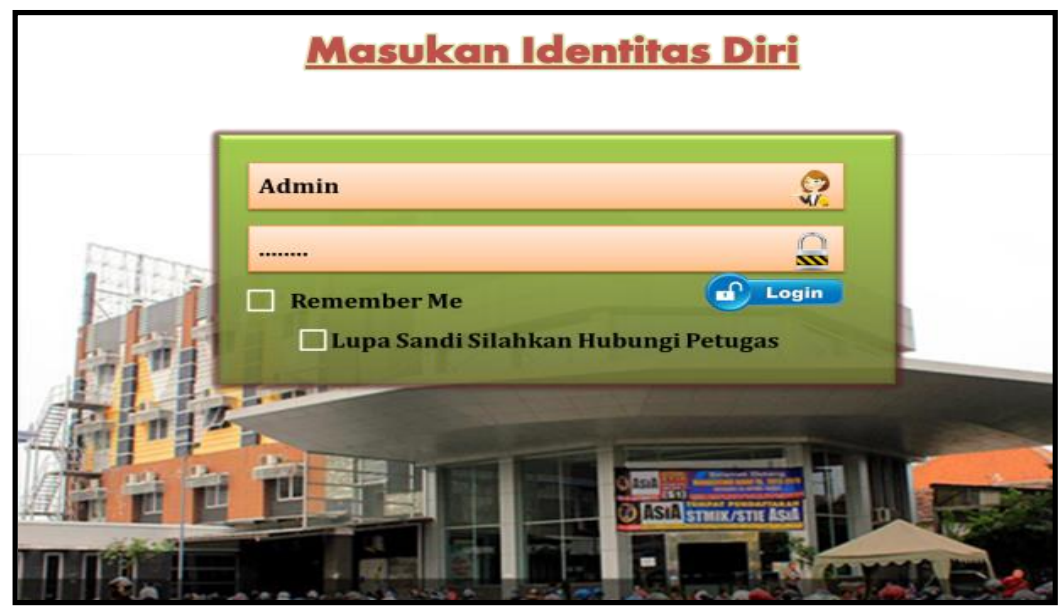

Gambar 5. Form Login

\subsection{Form Home}

Pada form home merupakan halaman awal sebelum user dalam hal ini adalah dosen dan BAA. Jika user memilih menu dosen, maka sebelum melakukan absensi dosen harus terlebih dahulu mengisi nama dosen, mata kuliah yang diampuh pada hari itu serta jurusan dan kelas. Form home untuk dosen ditunjukkan pada gambar 6. Setelah mengisi form yang telah disediakan maka dosen dapat mengklik tombol ijin, sakit atau alpa sesuai dengan keadaan mahasiswa yang bersangkutan, kemudian dapat mengklik tombol simpan setelah dosen telah melakukan absensi. Halaman proses presensi ditunjukkan pada gambar 7 .

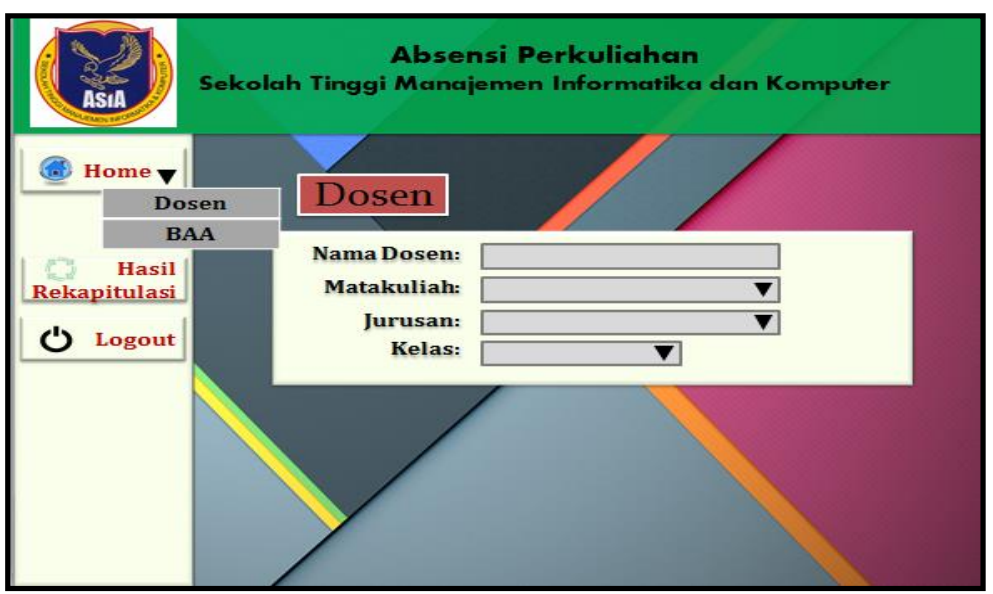

Gambar 6. Form Home untuk Dosen 


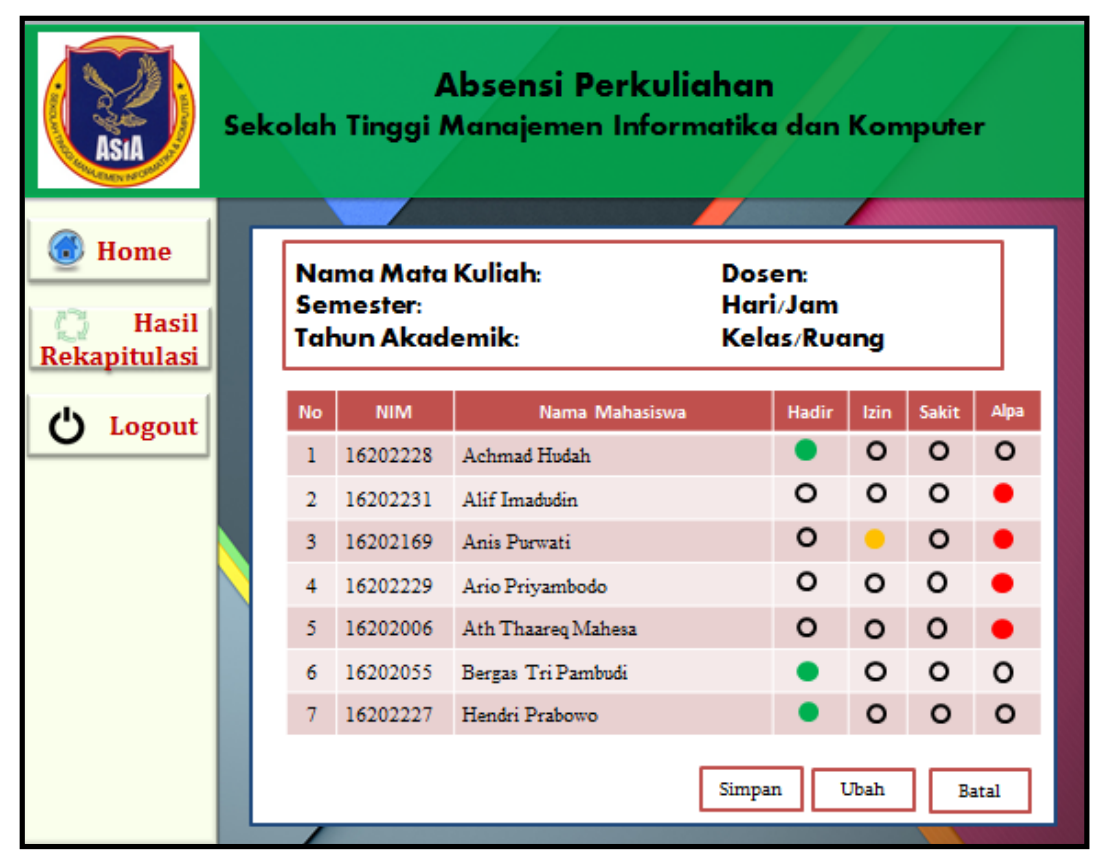

Gambar 7. Halaman Proses Presensi

\subsection{Form Hasil Rekapitulasi}

Pada form hasil rekapitulasi, user dapat melihat hasil akhir apakah mahasiswa bersangkutan memenuhi syarat untuk mengikuti Ujian Tengah Semerter (UTS) maupun Ujian Akhir Semester (UAS). Terlebih dahulu dosen mengisi form yang disediakan yaitu memilih jurusan dan mata kuliah yang ditunjukkan pada gambar 8 . Setelah mengisi form maka dosen akan di bawah ke halaman hasil keseluruhan presensi mahasiswa, di mana form tersebut akan menampilkan total kehadiran mahasiswa yang nantinya dapat dijadikan sebagai acuan untuk menentukan mahasiswa tersebut berhak mengikuti UTS dan UAS atau tidak. Form hasil rekapitulasi ditunjukkan pada gambar 9 .

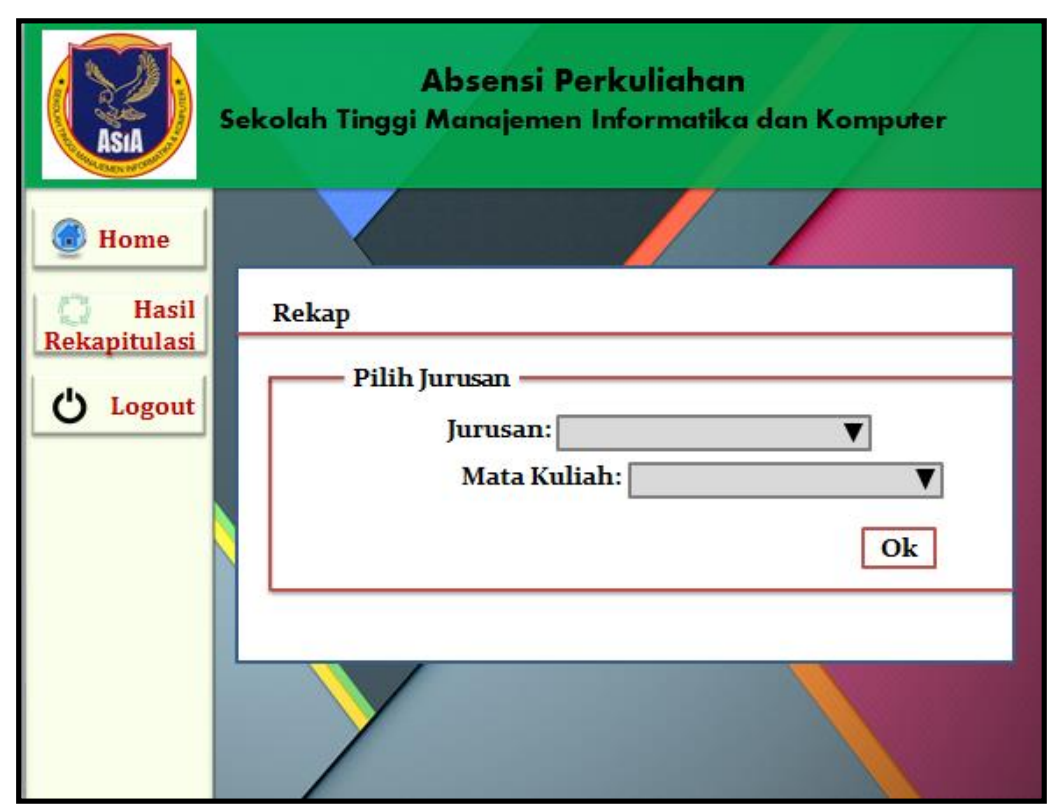

Gambar 8. Form Rekap 


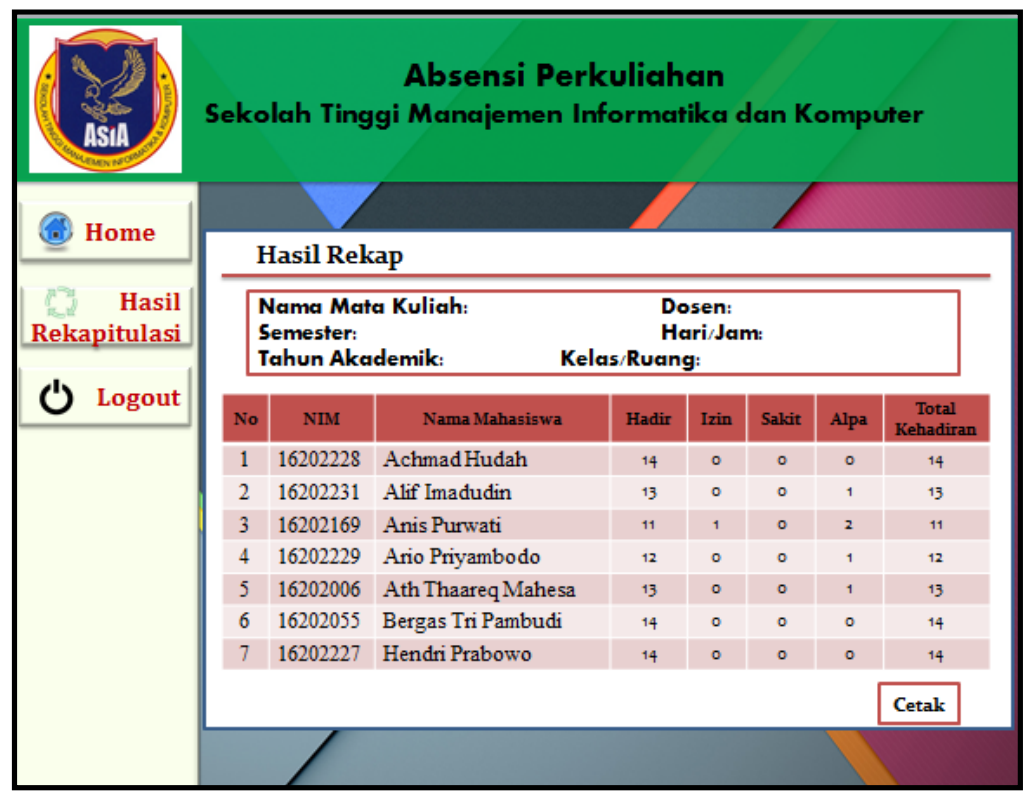

Gambar 9. Form Hasil Rekapitulasi

Sedangkan user dalam hal ini BAA, untuk melihat hasil rekapitulasi harus memilih menu BAA pada form home kemudian mengisi nama dosen, matakuliah, jurusan dan kelas. Kemudian akan di bawah ke halaman hasil rekapitulasi absensi dosen yang telah diinput sebelumnya. Untuk form home BAA dapat dilihat pada gambar 10 dan untuk form hasil rekapitulasi gambar 11. Tidak ada perbedaan form hasil rekapitulasi antara dosen dan BAA hanya saja alur untuk melihat hasil rekapitulasi absensi yang berbeda. Jika dosen ingin melihat hasil rekapitulasi harus mengisi form pada gambar 8 sedangkan BAA untuk melihat hasil rekapitulasi cukup mengisi form yang tertera pada gambar 10.

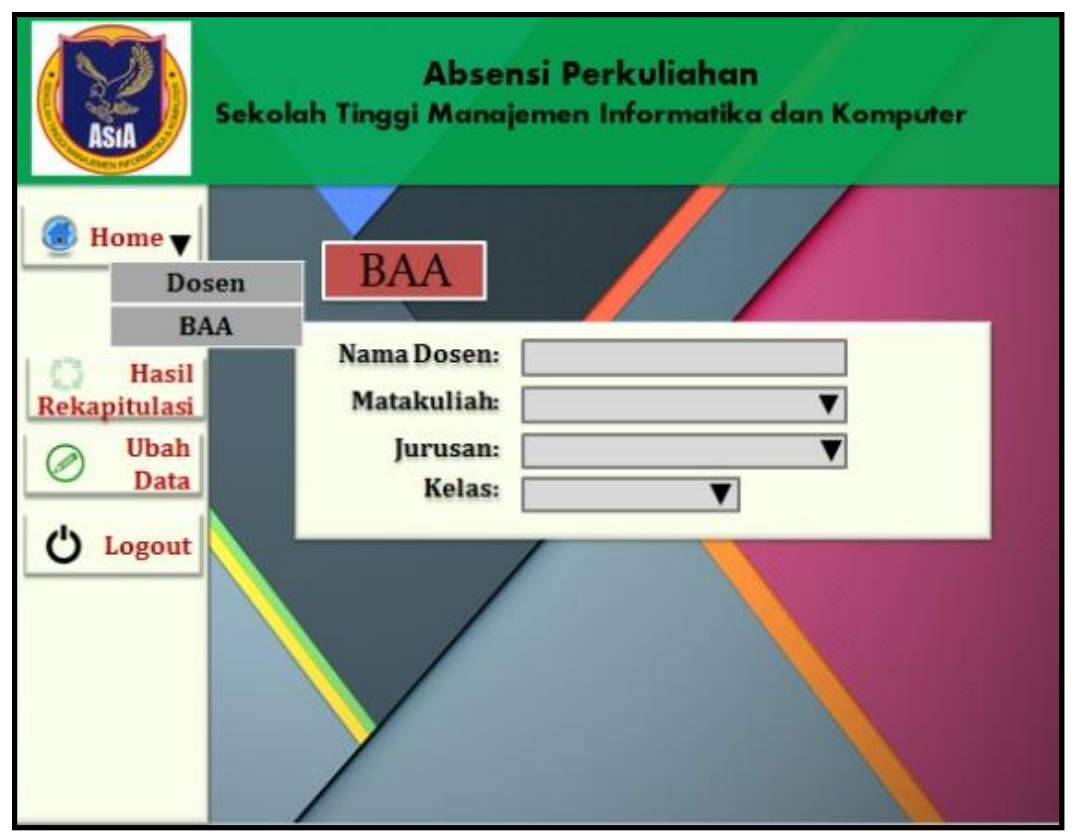

Gambar 10. Form Home untuk BAA

Jika hasil rekapitulasi akan di cetak maka user memilih tombol cetak maka sistem akan membawa user pada form cetak yang di tunjukkan pada gambar 11. 


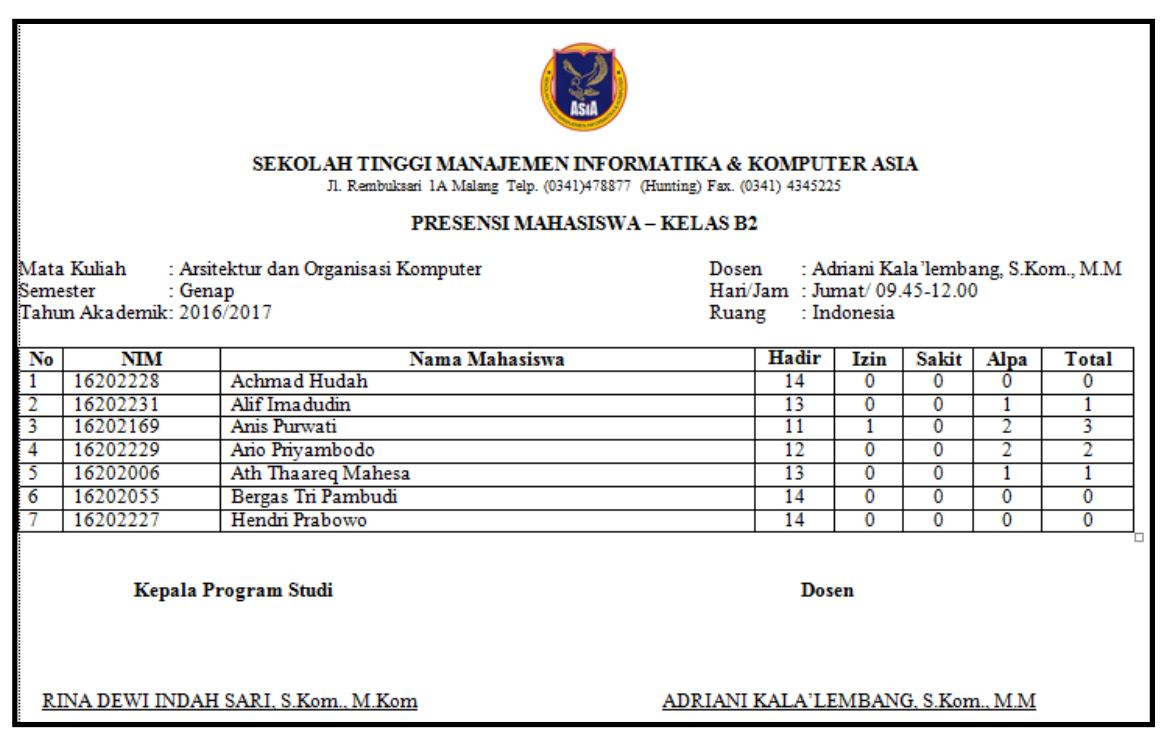

Gambar 11. Form Cetak Rekapitulasi Absensi

\subsection{Form Ubah Data}

Form ubah data hanya bisa digunakan oleh BAA, dimana form ini BAA dapat menambah data mahasiswa. Fungsi ini dapat digunakan apabila terdapat mahasiswa di kelas yang tidak terdaftar di absen. Maka pihak BAA dapat memasukkan nama mahasiswa tersebut dalam daftar absensi di kelas yang bersangkutan. Form untuk ubah data dapat dilihat pada gambar 12.

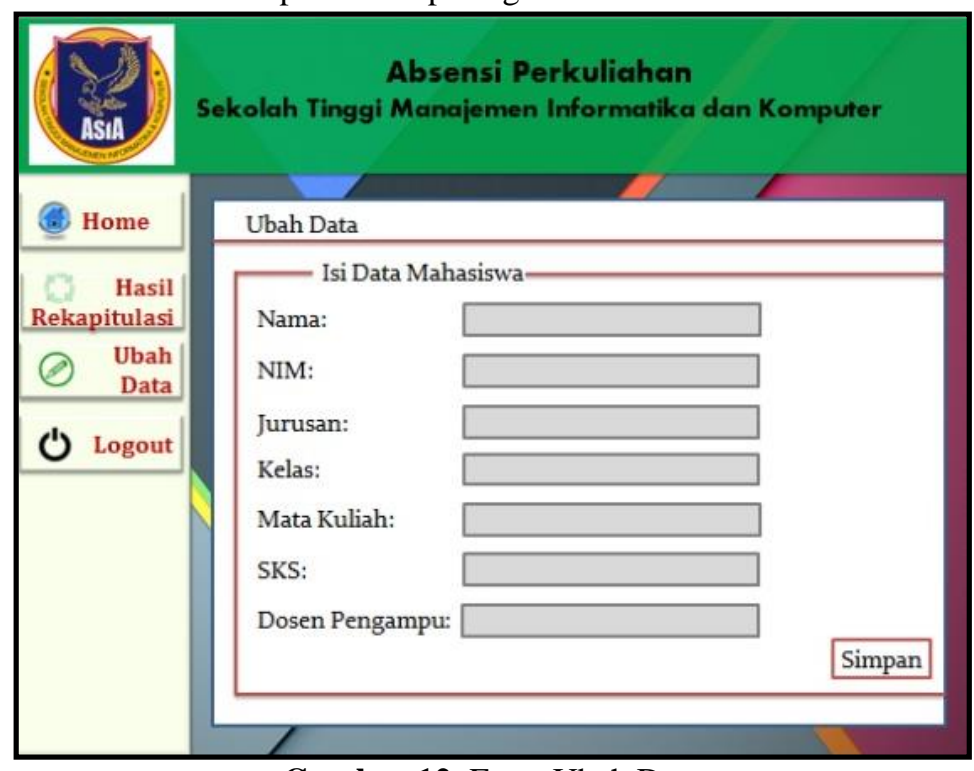

Gambar 12. Form Ubah Data

\subsection{Form Log out}

Form ini berfungsi jika user akan melakukan logout atau keluar dari sistem. Jika menu ini di klik, maka akan munculpertayaan konfirmasi untuk keluar dari sistem, bila disetujui maka sistem akan keluar dan user yagn mengakses sistem tersebut harus kembali melakukan $\log$ in dari awal. Form log out dapat dilihat pada gambar 13. 


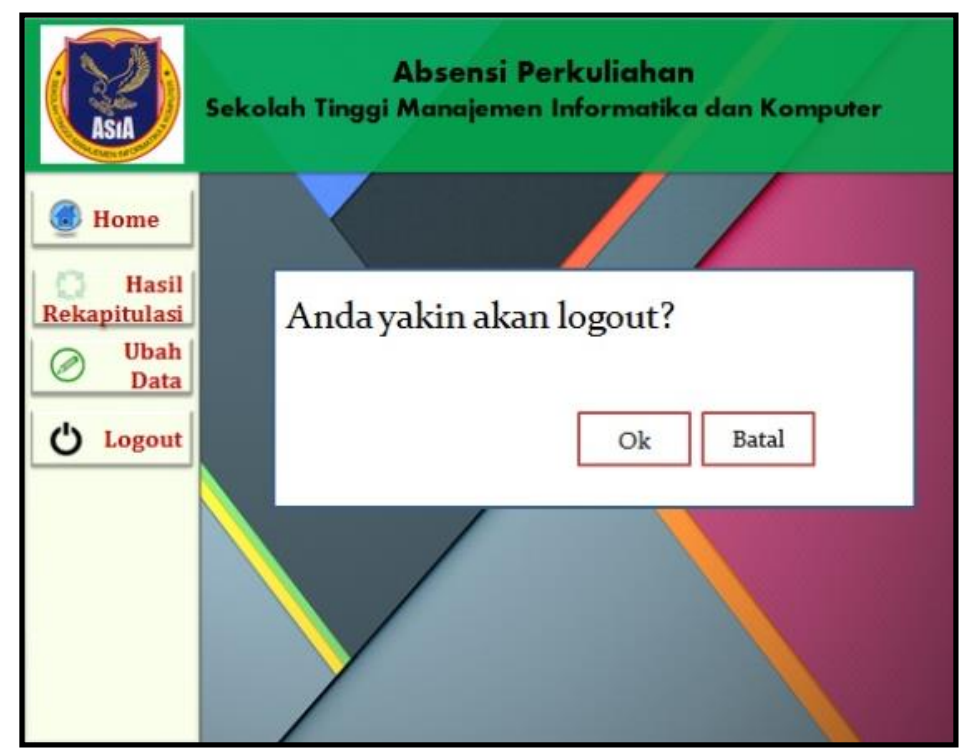

Gambar 13. Form Log out

\section{PENGUJIAN}

Uji validitas aplikasi ini dengan menggunakan metode Blackbox Testing. Metode uji coba Blackbox memfokuskan pada keperluan fungsional dari software.

\begin{tabular}{|c|l|c|}
\hline Aksi User & \multicolumn{1}{|c|}{ Reaksi Sistem } & Hasil Pengujian \\
\hline Menekan Form Login & $\begin{array}{l}\text { Memanggil halaman login dimana user memasukkan } \\
\text { user name dan password }\end{array}$ & Sesuai \\
\hline
\end{tabular}

Hasil pengujian fungsional form login menunjukkna bahwa ketika user melakukan proses login, reaksi sistem yang ditunjukkan yaitu menampilkan halaman login kemudian user dapat mengisi user name dan password. Berdasarkan hal tersebut dapat dikatakan bahwa hasil pengujian fungsional form login adalah sesuai.

\begin{tabular}{|c|l|c|}
\hline Aksi User & \multicolumn{1}{|c|}{ Reaksi Sistem } & Hasil Pengujian \\
\hline Menekan Form Home & 1. $\begin{array}{l}\text { Menampilkan tab Dosen dan BAA } \\
\text { 2. } \begin{array}{l}\text { Mengisi form nama dosen, matakuliah, jurusan } \\
\text { dan kelas }\end{array}\end{array}$ & Sesuai \\
& 3. Mengisi presensi hadir, izin, sakit, alpa & \\
\hline
\end{tabular}

Hasil pengujian fungsional form home menunjukkna bahwa ketika user menekan tombol form home, maka reaksi sistem yang ditunjukkan adalah menampilkan tab dosen dan BAA, mengisi form dan melakukan pengisian presensi. Berdasarkan hal tersebut dapat dikatakan bahwa hasil pengujian fungsional form home adalah sesuai.

\begin{tabular}{|c|c|c|}
\hline Aksi User & Reaksi Sistem & Hasil Pengujian \\
\hline $\begin{array}{l}\text { Menekan Form Hasil } \\
\text { Rekapitulasi }\end{array}$ & $\begin{array}{ll}\text { 1. } & \text { Menampilkan form rekap } \\
\text { 2. } & \text { Mengisi jurusan dan mata kuliah } \\
\text { 3. } & \text { Menampilkan hasil rekapitulasi }\end{array}$ & Sesuai \\
\hline $\begin{array}{ll}\text { Form } & \text { Rekapitulasi } \\
\text { BAA } & \end{array}$ & $\begin{array}{l}\text { 1. Menampilkan form home untuk BAA } \\
\text { 2. Memasukkan mana dosen, matakuliah, jurusan } \\
\text { dan kelas } \\
\text { 3. Menampilkan hasil rekapitulasi } \\
\text { 4. Mencetak hasil rekapitulasi }\end{array}$ & Sesuai \\
\hline
\end{tabular}

Hasil pengujian fungsional form hasil rekapitulasi dan form rekapitulasi untuk BAA yang ditampilkan menunjukkan bahwa reaksi sistem yang ditunjukkan berdasarkan aksi user sudah sesuai. Berdasarkan hal 
tersebut dapat dikatakan bahwa hasil pengujian fungsional form hasil rekapitulasi dan form rekapitulasi untuk BAA adalah sesuai.

\begin{tabular}{|l|l|c|}
\hline \multicolumn{1}{|c|}{ Aksi User } & \multicolumn{1}{c|}{ Reaksi Sistem } & Hasil Pengujian \\
\hline Menekan Form Ubah & $\begin{array}{l}\text { 1. } \begin{array}{c}\text { Menampilkan form ubah data } \\
\text { Data }\end{array} \\
\text { 2. Mengisi data mahasiswa diantaranya nama, NIM, } \\
\text { jurusan, kelas, matakuliah, SKS dan dosen } \\
\text { pengampuh }\end{array}$ & Sesuai \\
\hline
\end{tabular}

Hasil pengujian fungsional form ubah data yang ditampilkan menunjukkan bahwa reaksi sistem yang ditunjukkan berdasarkan aksi user sudah sesuai. Berdasarkan hal tersebut dapat dikatakan bahwa hasil pengujian fungsinal form hasil rekapitulasi dan form rekapitulasi untuk BAA adalah sesuai.

\begin{tabular}{|c|c|c|}
\hline Aksi User & \multicolumn{1}{|c|}{ Reaksi Sistem } & Hasil Pengujian \\
\hline Menekan Form Log out & $\begin{array}{l}\text { 1. Memanggil halaman logout } \\
\text { 2. Menampilkan kotak dialog untuk menghentikan } \\
\text { aplikasi atau tetap berada pada aplikasi }\end{array}$ & Sesuai \\
\hline
\end{tabular}

Hasil pengujian fungsional log out menunjukkan bahwa ketika user menekan tombol log out, reaksi sistem yang ditunjukkan adalah menampilkan kotak dialog yang menuntuk user untuk memilih kelur aplikasi atau tetap berada pada aplikasi.

\section{KESIMPULAN}

Dari hasil perancangan aplikasi dapat disimpulkan hal-hal sebagai berikut:

a. Dengan dibangunya aplikasi pengolahan presensi mahasiswa dengan metode Low Fidelity Prototype, maka dapat dihindari kecurangan yang dilakukan mahasiswa saat presensi dijalankan.

b. Dapat dengan cepat membantu tata usaha dalam merekapitulasi serta dapat meminimalisir kesalahan dalam perekapan.

c. Kebutuhan user, yang terdiri dari dosen dan tata usaha dapat terpenuhi karena informasi kehadiran mahasiswa dapat dimonitoring secara real time.

\section{SARAN}

Berdasarkan perancangan yang dilakukan maka saran untuk pengembangan selanjutnya adalah pihak pengembang dapat merealisasikan dalam bentuk real untuk mendukung proses perkuliahan di STMIK ASIA Malang dengan menambahkan fitur-fitur serta menambahkan user sehingga bukan hanya dosen dan pihak tata usaha yang dapat memantau melainkan juga dapat dipantau oleh ketua program studi.

\section{DAFTAR PUSTAKA}

Noval Aditya Muhammad, Febriliyan S dan Radityo Prasetianto. (2013). Pembuatan aplikasi perkuliahan berbasis fingerprint (study kasus :jurusan system informasi institute teknologi sepuluh nopember Surabaya).Jurnal Teknik POMITS System Informasi Fakultas Teknologi Informasi Institute Teknologi Sepuluh Nopember (ITS) Surabaya.

Hartono Puji, Tri Listyorini dan Ahmad Jzuli. (2015). Aplikasi Pengolahan Presensi Mahasiswa Magang Di Perpustakaan Universitas Muria Kudus. Posiding SNATIF Program Studi Teknik Informatika Fakultas Teknik Universitas Muria Kudus. Gondangmanis Jawa tengah.

Yusuf Muhammad, Hari Ginardi dan Adhatus Solichah A.(2016). Rancangan Bangaun Apalikasi Absensi Perkuliahan Mahasiswa Dengan Pengenalan Wajah. Jurnal Teknik Informatika, Fakultas Teknologi Informatika, Institute Teknologi Sepuluh Nopember Surabaya.

Mulyandi M.Rachmadi, Esa Wijayanti, Cynthia Ayu Wulan Dini dan Nina Rahayu. (2014).Informasi Sysyem Design And Prototype Absensi With Application Web Base Kecamatan Batu Ceper Tangerang. SeminarNasional Teknologi Dan Multimedia 2015.

Sulistiyo Wahyu, Budi Suyanto, Idhawati Hetiningsih, Mardiyono, Sukamto.(...). Rancang Bangun Protitipe Aplikasi Pengenalan Wajah Untuk System Absensi Akternatif Dengan Metode Haar Like Feature Dan Eigenface. Jurnal Teknik Elektro. Jurusan Teknik Elektro Politeknik Negri Semarang.

Sara Streng, 2008. High and Low Fidelity Prototyping. PPT winter semester 2007/2008 Ludwing Maximilians Universitat Munchen . 